\title{
A prece cura?
}

\author{
Fernando César Paulino-Pereira*
}

\begin{abstract}
Resumo: O hamem acometido de crise, dor e sofrimento encontra-se fragilizado e vê-se diante de uma situação ou de um momento que o conduz à perda de sentidos para a sua existência. No afã de ressignificar sua vida, este mesmo homem encontra na experiência religiosa um lugar que pode lhe proporcionar ou propiciar uma possível reestnuturação dos significadbs, valores e sentidbs perdidbs e/ou abaladbs pela situação de crise. A fé e a oração/prece podem ser apresentadas ao homem como uma possível mediação dessa movimentação à autotranscendência, em relação ao sentido do seu existir, porém não como cura de suas enfermidades.
\end{abstract}

Palavras-chave: experiência religiosa; oração/prece; crise.

\section{Considerações iniciais}

Este artigo propõe-se, em uma abordagem fenomenológica existencial, a compreender o fenômeno da experiência religiosa (no caso aqui proposto, a experiência da oração/prece) para o homem que, quando em angústia, dor ou sofrimento, busca significados para sua existência, no âmbito do Ser - entendendo a fé como mediação da relação entre o homem e o divino.

Buscamos compreender como a situação de crise e angústia estabelecidas vem potencialmente abalar os significados da existência. A existência humana é sempre geradora de conflitos e suas conseqüências. ${ }^{1} \mathrm{O}$ homem está sempre à procura de auto-realização em todas as esferas de sua existência. Auto-realização esta que abrange, inclusive, a necessidade do conhecimento do seu próprio ser. E assim, como homem, possibilitar a extensão de seu poderser. $^{2}$

\footnotetext{
* Doutorando em Psicologia Social pela PUC-SP, mestre em Ciência da Religião pela Umesp, psicólogo pela Unimep e professor de Psicologia Social - Unimep. E-mail: epifania@directnet.com.br

1. Uma existência geradora de conflitos, no sentido em que sempre há na existência a constante possibilidade de haver oposição aos impulsos do ser existente.
}

Ao referirmo-nos à angustia, estamos nos atendo ao estudo de um estado momentâneo de crise em que se encontra o indivíduo, e que por meio de mecanismos de autoquestionamento e análise, possibilita a expansão do conhecimento do mundo e de si próprio, inclusive de si-própriono-mundo.

Os eventos que questionam e quebram as crenças e valores mais íntimos e pessoais do homem podem provocar crises e desorientação existencial. Como ser consciente da procura de sua auto-realização, o homem necessita conhecer os respectivos valores de seus propósitos, como homem, e como ser.

Esses valores, quando em disposição ao homem detentor de desejos, necessidades e apetites, transformam-se, entre outras coisas, em crenças $^{3}$ e, quando direcionados para o

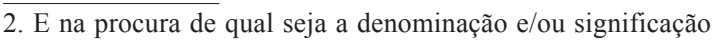
pessoal/coletiva, do termo auto-realização, a possibilidade da citada oposição a esse impulso pode ocorrer. Aqui admitimos essa ocorrência, e uma das conseqüências mais freqüentes nesse caso é o abalo da valorização; o valor de algo estabelecido como padrão ideal é ameaçado ou minimizado ou mesmo (quando não) negado.

3. Crenças essas que têm graus de representatividade e conseqüentes graus de valoração correspondentes a sua inserção e localização.
} 
conhecimento do todo fora do ser, que é o homem que tem uma crença, transformam-se em valores dotados de signos e significados de uma ampla gama que vai do social ao psicológico, do cultural ao religioso, do ético ao estético etc.

Ao ver-se diante de questões que surgem durante sua existência, crê o homem dispor de uma ferramenta para sua evolução, satisfazer seus apetites e, no campo religioso, torná-lo apto para decidir entre o bem, que orienta a perfeição e beatitudes, e o mal, que lhe imputa defeitos, pecados ou imperfeições. Por perfeição ou imperfeições, entendemos o atingir ou não os propósitos contidos nas leis divulgadas e ensinadas pelo coro religioso.

Dessa forma, cada etapa da vida do ser humano está constituída pelo predomínio ou destaque de crenças específicas que trazem em si a possibilidade de, a partir da realidade em que o homem se encontra naquele momento, ajudá-lo a rever-se a si próprio e a avançar. A realidade, sendo autogeradora, altera nossas crenças anteriores, possibilitando dessa forma a formação de novas crenças e projeções.

A angústia, a dor e o sofrimento abalam os projetos de vida do homem, pois, no decorrer da vida do indivíduo, há períodos em que as rupturas com origem em alguma crise fazem com que algum tipo de significado da existência humana passe por mudanças bruscas, não compreendidas de imediato, gerando a perda de sentido. Em tal processo de ruptura, o homem procura não apenas alívio para tal situação que associa à dor, mas também a compreensão desse todo ocorrido, quase como a procura por um estado de proteção - e o faz mediante a oração/prece.

Quando o homem passa por um processo de mudança brusca da realidade cotidiana aceita, ou em outras palavras, quando ocorre um processo de tomada de experimentação de um "algo sobre-humano", superior, mais organizado e direcionado ao sentido naquele momento específico de crise ou ruptura - e esse "algo sobrehumano" é relacionado com uma potência também sobre-humana e, além disso, origem e geradora de tudo o que se possa perceber e/ou pressentir -, tem-se a raiz da experiência religiosa.

Geralmente, quando em um estado de crise, dor, sofrimento e angústia, o homem tem seus sentidos abalados e seu senso de orientação temporal deslocado. Passada essa etapa, por meio da experiência da oração/prece, tem-se o sentimento de alívio e felicidade, que aumenta a confiança própria através do ajustamento das faculdades a uma visão mais vasta.

Segundo Romero (1988), a religião pode participar do processo de auto-realização do homem, pois, na base de quase todas, "está a crença de um primeiro fundamento para a existência humana e de uma finalidade última para a vida, fundamento e finalidade estabelecidos por um Ser Supremo" (1998, p. 20). Contra o desamparo e a solidão o homem religioso invoca a proteção divina. $\mathrm{O}$ elemento "fé", constituído pela relação homem-Deus, apresenta-se como componente essencial da religiosidade, no qual o homem religioso valida aquilo que ele acredita. A fé serve de fidelidade à verdade religiosa. ${ }^{4}$

\section{O sofrimento: crise que abala os signifi- cados da existência}

A ansiedade faz parte da existência humana; é ela que faz com que o homem nunca se conforme com o que ele é e se coloque sempre em busca da plenitude. O homem, ao tomar consciência da finitude, angustia-se e entra em estado de ansiedade.

A qualquer momento, a ansiedade pode fazer-se presente na manifestação ou na possibilidade do não-ser. O sofrimento coloca em falha o processo homeostático (cf. Perls, 1988) do homem, levando-o a um desequilíbrio existencial. O homem coloca-se de frente à ameaça do nãoser, que é idêntica à finitude.

Finitude com consciência é ansiedade. Como a finitude, a ansiedade é uma qualidade ontológica. Não pode ser derivada; só pode ser vista e descrita. Devem ser distinguidas ocasiões nas quais surge a ansiedade, da própria ansiedade. Como uma qualidade ontológica, a ansiedade é tão onipresente quanto a finitude. A ansiedade é independente de qualquer objeto especial que a possa provocar; é dependente tão somente da ameaça do não-ser que é idêntica à finitude. (Tillich, 1987, p. 163)

4. Uma sugestão de leitura: HABERMAS, J. Verdade e justificação. São Paulo: Loyola, 2004. 
A finitude inclui experiências como o sofrimento, a solidão e a morte, além da ameaça de perda de sentido e de desespero (cf. Josgrilberg, s/d). O ser limitado pelo não-ser é finitude (cf. Tillich, 1987). O homem, acometido pelo sofrimento, vê-se ameaçado pelo não-ser, que o leva a um choque ontológico, choque este que abala as estruturas e os significados do existir desse indivíduo.

A ameaça do não-ser, possuindo a mente, produz o choque ontológico. Nele é experimentado o lado negativo do mistério do Ser seu elemento abismal. Choque aponta para um estado de mente na qual a mente é tirada de seu equilíbrio normal, abalada em sua estrutura. (Tillich, 1987, p. 100)

A mente, tirada do seu equilíbrio normal, abala a estrutura da consciência, que perde a intencionalidade, pois se encontra limitada pelo não-ser. A situação de sofrimento, de dor, de morte é experimentada como ameaça ao ser e a seu sentido de vida, forçando o homem a buscar nova possibilidade de transcendência, de olhar para si mesmo tomando consciência da finitude e experimentando suas potencialidades limitadas.

O Ser limitado pelo não-ser é finitude [...]. A finitude é experimentada em nível humano; o não-ser é experimentado como a ameaça ao Ser [...]. Para experimentar a sua finitude, o Homem deve olhar para si mesmo do ponto de vista de sua infinitude potencial [...]. O eu finito enfrenta um mundo; o indivíduo finito tem o poder de participação universal; a vitalidade do Homem está unida a uma intencionalidade essencialmente ilimitada [...]. Todas as estruturas da finitude forçam o Ser finito a transcender-se a si mesmo e, exatamente por essa razão, a tomar consciência de si mesmo como finito [...]. O infinito é um conceito diretivo, não constitutivo. Ele dirige a mente a experimentar suas próprias potencialidades ilimitadas [...]. (Tillich, 1987, p. 162-163)

$\mathrm{O}$ homem em crise, assolado pela dor e pelo sofrimento, vê-se novamente diante de uma falta de sentido para sua existência, e este estado leva-o à ansiedade ontológica. Somente o homem é capaz de responder à questão ontológica, isto porque experimenta, seja direta ou indiretamente, a estrutura do Ser e de seus elementos. A ansiedade com respeito à falta de sentido é a forma caracteristicamente humana da ansiedade ontológica (cf. Tillich, 1987).

A relação que este homem, acometido de sofrimento e dor, estabelece com o mundo, a relação das polaridades eu-mundo, baseada na razão subjetiva do eu, encontra-se repleta de ambigüidades, visto que o ser que sofre perde a sua subjetividade. A existência desse ser encontra-se fragmentada pelo sentimento de vazio. "A vida está marcada pela ambigüidade" (Tillich, 1987, p. 346).

As ambigüidades da vida são manifestas sob todas as dimensões, em todos os processos e em todos os reinos da vida. A busca da vida sem ambigüidades está latente em toda parte. Todas as criaturas anseiam por uma realização não-ambígua de suas possibilidades essenciais; mas, somente no Homem como portador do espírito, as ambigüidades da vida e a busca da vida sem-ambigüidades se tornam conscientes. (Tillich, 1987, p. 466)

As funções das categorias de finitude vão mudando de acordo com as condições da existência, e o tempo é a principal categoria da finitude (cf. Tillich, 1987). Nessa categoria, o Ser deve prevalecer sobre o não-ser. O homem sofrido, em crise, tem a possibilidade da resistência e da coragem do desespero. Coragem de ser - ser como ser finito que pode transcender olhando para si mesmo.

A natureza categorial da finitude, incluindo o tempo, espaço, causalidade e substância, é válida como estrutura na totalidade da criação. Mas a função das categorias de finitude muda sob as condições da existência. Nas categorias, a união de Ser e não-ser em todos os seres finitos é manifesta. Portanto, elas produzem ansiedade; mas podem ser afirmadas pela coragem, se é experimentada a predominância do Ser sobre o não-ser. No entanto as categorias controlam a existência e produzem uma dupla reação com relação a elas - resistência e desespero. (Tillich, 1987, p. 297)

O tempo expressa não só a união de Ser e não-ser, mas também a união de ansiedade e 
coragem. Ser significa presente - presente em abundância, vida plena, sem sofrimento e sem dor. O presente com dor e sofrimento torna-se presente ilusório, no qual o ser é conquistado pelo não-ser e isso provoca ansiedade, que deve ser transcendida pela coragem de ser.

O tempo faz parte do homem, ele é o homem. Não há como escapar do tempo. Isso causa sensação de impotência no homem que sofre, pois este se encontra em estado de fragilidade e debilidade. A experiência do tempo não produz o desespero, mas, sim, o fracasso de opor-se a ele. Não é a experiência do tempo como tal que produz o desespero, antes, porém, é o fracasso de opor resistência contra o tempo (cf. Tillich, 1987).

\section{A experiência religiosa: fonte de cura?}

A psicologia da religião e o estudo psicológico da experiência religiosa surgem com Willian James, nos EUA, no final do séc. XIX. James centrou seus estudos na conversão religiosa. Segundo ele, a característica central da conversão

[...] é a perda de todas as preocupações, o sentido de que tudo está finalmente bem conosco, a paz, a harmonia, a disposição de ser, ainda que as condições exteriores permaneçam as mesmas. A segunda característica é o sentido de perceber verdades dantes não conhecidas. Os mistérios da vida tornam-se lúcidos. (James, 1991, p. 159)

Os sintomas pré-conversão religiosa, segundo James, são "[...] sentido de inacabamento, senso do pecado, ansiedade a respeito da vida futura, angústia tocante a dúvidas" (James, 1991, p. 131, enquanto o resultado da conversão representa "[...] alívio feliz e objetividade à medida que aumente a confiança própria através do ajustamento das faculdades à visão mais vasta" (James, 1991, p. 131-132).

Em momentos de ansiedade, angústia, dor e sofrimento, sentindo-se responsável por tudo que o assola e o remete ao sentimento de culpa, o homem experimenta a conversão que, para James, é "antes um processo de lutar para livrarse do pecado do que de forcejar por alcançar a retidão" (James, 1991, p. 137).
O homem vê o pecado, segundo Tillich (1987), como:

Condição universal do ser humano de estar alienado de sua fonte divina. O pecado envolve nossa personalidade como um todo, nossa responsabilidade, nossa culpabilidade pessoal, nosso atos, nossa vontade. A percepção de nossa distância e de nossa ruptura em relação a Deus é seguida de um forte sentimento de cumplicidade e de culpabilidade ontológica e revelada. O sentimento de auto-satisfação com a ruptura é também o sentimento de perda do essencial. Ao mesmo tempo persistimos como coragem, como esperança, como dever, como aceitação do destino comum, etc. São resultados do pecado a descrença, a hybris, a concupiscência, etc. Estrutura de pecado - a ação e as formas de vida (situações) e culturais que o ser humano cria para viver estão marcadas pela alienação e por forças violentas de destruição. A capacidade de o homem desenvolver as estruturas de existência e de cultura a partir de seu poder de transcender todas as coisas e ainda de autotranscendência torna as estruturas do pecado uma conexão capaz de males infinitos e inesperados, mesmo onde a sua vontade é eticamente boa. (Apud Josgrilberg, s/d, p. 8)

Assim é o poder divino que resgata esse homem do fundo do "poço" e lhe possibilita a transcendência - a inserção ou o desvelar de uma vida autêntica. "Deus é o poder de ser, resistindo e conquistando o não-ser" (Tillich, 1987, p. 228). A fé nesse Deus onipotente é que dá ao homem o sentimento de alívio e de vida eterna.

A eternidade

[...] assume o lugar de algo como onitemporalidade, que seria a analogia para onipotência, onipresença, etc. Isto pode ser uma conseqüência do caráter central do tempo como categoria da finitude. Só é divino aquilo que dá coragem para suportar a ansiedade da existência temporal. Onde a invocação "Deus Eterno" significa participação naquilo que conquista o não-ser da temporalidade, ali foi experimentada a eternidade. (Tillich, 1987, p. 229-230)

A eternidade é uma qualidade da vida divina, não podendo ser atribuída a um ser condenado 
pelo pecado; já a conversão é a experiência pela qual o homem experimenta a regeneração e o perdão de seus pecados, livrando-se da condenação, sendo resgatado do não-ser e tendo a possibilidade de vida autêntica, de transcendência. "A graça, como infusão do amor, é poder que supera a alienação" (Tillich, 1987, p. 281). Isso se dá na reconciliação pessoal do homem com Deus; mas a experiência de separação com relação a nossa eternidade é o estado de desespero que é

[...] estado de conflito inevitável. É o conflito, por um lado, entre o que se é potencialmente e portanto dever-se-ia ser, e por outro lado o que se é em combinação de liberdade e destino. A dor do desespero é a agonia de ser responsável pela perda do sentido de nossa existência e de ser incapaz de redescobri-lo. (Tillich, 1987, p. 302)

Dessa forma, esse homem acaba sendo então trancado em si mesmo, em conflito com seu próprio ser.

No encontro com Deus, na conversão religiosa, na oração/prece, ao homem é dada a possibilidade de transcendência, de vida autêntica na regeneração, pela graça, mediante a fé. $\mathrm{O}$ homem transcende no seu encontro com o divino, que pode livrá-lo do não-ser, possibilitando-lhe assim o ser autêntico - ressignificando sua vida, mas não curando suas enfermidades (cf. Habermas, 2004, cap. 7).

\section{Ressignificar a existência: a conversão existencial}

\section{A conversão existencial}

[...] consiste em renunciar à categoria de apropriação, que só pode reger a relação do Para-si com as coisas, para introduzir na relação interna da Pessoa a relação de solidariedade, que mais tarde será modificada em solidariedade com os outros. (Sartre, 1983, p. 495-496)

A conversão existencial pode ser considerada como uma forma de estar-no-mundo comprometida com a história e com o momento (tempo/espaço) em que se vive. É existência autêntica, "em termos de assumir o que se quer fundar. $\mathrm{O}$ que se pretende fundar é a realidade humana; em conseqüência, assumir essa realidade é reivindicar a responsabilidade do que acontece. Assumir a liberdade e a facticidade" (Barría, s/d, p. E).

Alcançar a conversão - modo autêntico de existência - e ao mesmo tempo fazer que haja ser. É busca constante por ser, fazendo com que esta busca se plenifique no encontro do Ser com o Outro; pois o "Outro é o mais importante para o conhecimento que temos de nós mesmos" (Barría, s/d, p. H). A conversão se dá no endireitamento e no estreitamento da relação com o outro, no assumir nossa época, nossa historicidade.

Assumir a época e a historicidade é alcançar a autenticidade existencial (cf. Sartre, 1983). Ou seja, o sentido da conversão é a rejeição da alienação. A vida autêntica é, para Heidegger, um "passado-futuro; simultânea e solidariamente regresso ao passado e pro-jeção para o futuro, isto é, para a morte e para o nada" (Jolivet, 1961, p. 140).

Na conversão existencial, segundo Heidegger, o homem assume sua história e sua existência no mundo. "A historicidade do Dasein é a própria historicidade do mundo, a qual resulta da temporalização do Dasein e da exterioridade ou horizonte que é" (Jolivet, 1961, p. 149).

A não-conversão existencial seria a existência inautêntica, na qual o homem supõe que a sua própria historicidade deriva da historicidade do mundo, e não o contrário.

O homem inautêntico (não convertido).

[...] vive disperso na multitude do que se passa em cada dia e que para ele toma o aspecto de "destino" - de um destino que o domina e lhe impõe a própria forma de vida. A sua existência torna-se, assim, descontínua, constituída por pontos, ficando ele sem saber o que é que entrelaça e dá unidade à existência, quando não chega até a desconhecer que existe este princípio de unidade. (Jolivet, 1961, p. 150)

Ao converter-se (cf. Jolivet, 1961) existencialmente, o homem realiza o ato de transcender. Para Heidegger, a transcendência é

[...] uma estrutura fundamental da subjetividade, isto é, não é um modo de ser do Dasein como tantos outros, mas sim elemento consti- 
tutivo do próprio Dasein e, sob este aspecto, anterior a qualquer comportamento. O Dasein é, em si, transcendente, isto é, só existe e só pode existir ultrapassando. O Dasein ultrapassa os existentes no sentido do Ser inteligível de cada um deles. O Dasein transcende-se, portanto, a si mesmo, e transcende-se necessariamente. (Jolivet, 1961, p. 153)

Ao transcender, o homem mostra-se organizador do seu mundo. "O mundo é aquilo que o Dasein pro-jeta à sua frente vindo a ser o conjunto das relações que pode ter com os existentes, entre os quais existe" (Jolivet, 1961, p. 155). Porém, segundo Habermas, os filósofos

[...] devem deixar para os teólogos a tarefa de dar consolo nas situações-limite da existência. A filosofia não pode se apoiar no saber salvífico teológico, nem no saber clínico especializado, o que a impede portanto de prestar 'ajuda de vida', como o fazem a religião ou a psicologia. (2004,p. 323)

\section{A experiência de fé}

A fé coloca diante do homem o direito de ser e estar possuído pela presença do espiritual em uma abertura à transcendência. ${ }^{5}$ Não é aceitação de valores e afirmações de uma determinada manifestação religiosa e/ou autoridade religiosa, é, sim, estar possuído pelo Novo-Ser, em uma abertura à possibilidade de relação com Deus.

Fé não é aceitação de afirmações ou valorações fatuais baseadas na autoridade, mesmo que essa autoridade seja divina, pois nesse caso surgiria a pergunta: baseado em que eu chamo essa autoridade de autoridade divina? (Tillich, 1987,p. 485)

A fé tem estruturas que comportam metodologia de análise, ou seja, fundamentos ontológicos, ${ }^{6}$ fundamentos e metodologias estes obje-

5. Como em Goethe, quando escreve: “O ETERNO em tudo se faz sentir / Pois tudo no Nada deve cair / Se for insistir em Ser. Esse Nada, nadificante não é aceitação de valores... (Do poema "Eins und Alles", de 1821 - Das Ewige Regt Sich fort in allen: / Denn alles muss in Nichtszer / allen / Wemm es inn Sein behanen will - tradução nossa).

6. Heidegger perpassa essa condição de fundamentos ontológicos, ao assinalar que é a primeira alternância que o tos da teologia. Tudo o que, a partir do infinito, se projeta no finito, causando-nos preocupação última, e o que sente e sabe o homem de fé, esta relação é proveniente do Ser que existe em si, "causação" esta do fenômeno da fé. Neste sentido, Tillich (1987) diz:

[...] fé tem três elementos: primeiro, o elemento de abertura provocada pela Presença Espiritual; segundo, o elemento de aceitação apesar do abismo infinito entre Espírito divino e o espírito humano, e terceiro, o elemento de expectativa por uma participação final na unidade transcendente da vida sem-ambigüidade. Esses elementos estão incluídos uns nos outros, eles não se seguem sucessivamente, mas estão presentes onde quer que ocorra a fé. (p. 487)

Ela é "evidência imediata do Novo-Ser dentro e sob as condições de existência. Exatamente isso é garantido pela natureza da fé cristã" (Tillich, 1987, p. 332).

\section{A experiência de liberdade}

O homem tem a liberdade de escolha escolha esta que traça seu destino. A liberdade só é possível em interdependência com o outro pólo dessa relação - o destino. Todo pensador depende do chamado do Ser. A dimensão dessa dependência determina a liberdade de influências irrelevantes (cf. Heidegger, 1968).

O destino do homem é constituído pelas decisões tomadas e que serão tomadas durante toda a sua vida - é constituído pela liberdade. O homem tem a liberdade de responder ou não à graça proveniente de Deus - a fé é a resposta. É, ao responder à graça, que o homem possibilita a sua participação no Novo-Ser, trazendo para si a presença do Divino e traçando para si um destino de possibilidades.

Nosso destino é aquilo a partir do qual surgem nossas decisões. É a base indefinidamente ampla de nossa individualidade centrada. É a concreticidade de nosso Ser, que torna todas as nossas decisões nossas decisões. $\mathrm{O}$ destino

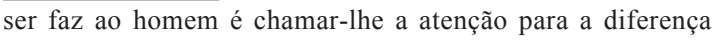
ontológica, ou seja, entre o fato em si de ser dos seres e o ser desse fato de ser ele mesmo, o Ser do Ser. E esses fundamentos e metodologias são objetos diretos da teologia. Cf. Heidegger, 1988, cap. 2 e 3. 
não é um poder estranho que determina aquilo que irá acontecer em mim. É minha própria pessoa, tal qual dada, formada pela natureza, pela história e por mim mesmo. Meu destino é a base de minha liberdade; minha liberdade participa da estruturação de meu destino. (Tillich, 1987, p. 158)

Na situação de crise e desespero, o homem vê-se sem destino, perde o foco de valores e permanece angustiado e ansioso. A perda do destino é a perda do próprio Ser. A fé entra na vida do homem como possibilidade de refazer seu destino, de reconstituir a força e a capacidade de transcendência do homem, para que ele tenha a liberdade de responder à graça salvífica de Deus. "Perder o próprio destino significa perder o sentido do próprio Ser. Destino não é fatalidade sem sentido. É necessidade unida a um sentido" (Tillich, 1987, p. 171).

A liberdade é experimentada pelo homem como responsabilidade de ter nas suas próprias mãos o seu destino, de conduzir sua vida e dar novos rumos à sua existência, mas este mesmo homem quando acometido pela dor e pelo sofrimento, mergulhado em uma existência inautêntica, perde o poder de direção, não sabendo usar de maneira centrada sua liberdade.

A fé tem a função de objetivar o uso da liberdade humana, restabelecendo ao homem o direito de usá-la como forma de poder ser ele próprio o dono de suas decisões. Assim, o homem poderá, com liberdade, responder à graça com fé, mudando o rumo do seu destino, e recuperando para si a existência autêntica.

Liberdade não é a liberdade de uma função (a vontade), mas do Homem, isto é, daquele Ser que não é uma coisa mas um eu completo, uma pessoa racional. Dever-se-ia falar da liberdade do Homem, indicando que cada parte e cada função que constitui o Homem como eu pessoal participa de sua liberdade. A liberdade é experimentada como deliberação, decisão e responsabilidade. (Tillich, 1987, p. 157-158)

Somente o homem existindo autenticamente consegue alcançar a liberdade centrada e ter em suas mãos a direção do seu destino. Somente o homem que tem liberdade tem um destino.

\begin{abstract}
A liberdade e destino em todo indivíduo estão unidos de tal forma que é impossível separar um do outro como é, conseqüentemente, separar o destino eterno de qualquer indivíduo do destino de toda raça e do Ser em todas as suas manifestações. Só quem tem liberdade tem um destino. (Tillich, 1987, p. 697)
\end{abstract}

\section{A oração/prece}

O homem religioso tem Deus como fundamento da estrutura do Ser - a tendência do homem é sempre voltar-se para Ele, uma tendência atualizante do Ser que busca a plenitude, a integridade, a transcendência.

Já que Deus é o fundamento do Ser, ele é o fundamento da estrutura do Ser. Ele não está sujeito a essa estrutura: a estrutura se fundamenta nele. Ele é essa estrutura, e é impossível falar dele a não ser em termos desta estrutura. Deus deve ser atingido cognitivamente através dos elementos estruturais do Ser-em-si. (Tillich, 1987, p. 201-202)

É através da oração/prece ${ }^{7}$ que o homem experimenta Deus. É através da oração/prece que o Ser em crise recebe a transcendência, a possibilidade de vida plena e abundante. $\mathrm{Na}$ experiência, Deus fala ao homem, que o ouve e o sente como próximo e não distante, mas como parte de si mesmo. "A experiência é o meio através do qual as fontes falam a nós, e através do qual podemos recebê-las" (Tillich, 1987, p. 42).

Ela é a possibilidade de contato com uma realidade que transcende a realidade concreta. É atualização do tempo (passado-presentefuturo) na vida do Ser em crise. É como uma inquietação religiosa, algo que só pode ser sentido e vivido pelo homem; que transporta o homem a uma outra dimensão de paz, alegria, resgate de uma existência inautêntica para uma existência autêntica, pois a experiência requer a presença de dois lados, o homem e Deus, ou seja, do divino com o humano, do infinito com o finito.

A experiência religiosa é uma forma de contato com uma realidade. A experiência religiosa pode

7. Oração/prece entendida aqui como uma das variedades da experiência religiosa. 
ser entendida como inquietação religiosa. É a experiência das dimensões do vazio que nos habita, seja ele aceito como mola propulsora de uma busca que não sabemos onde vai dar, seja ele negado por um raciocínio simples, de que se trata no fundo de uma sensação ilusória decorrente basicamente de nossa própria capacidade de pensamento abstrato. (Amatuzzi, 1997, p. 32)

$\mathrm{Na}$ experiência religiosa (oração/prece), o homem experimenta o Ser-em-si, que é o Ser de Deus, o absolutamente independente de nós, aquilo que é percebido como poder e glória. A presença de Deus que pertence ao homem. Para Tillich (o que não acontece em Heidegger),

(...) a experiência religiosa tem por objeto o transcendente, o divino, o absolutamente independente de nós, percebido enquanto poder e glória. $\mathrm{O}$ novo que surge com a experiência religiosa não é algo que pertence ao mundo das idéias, não é apenas um entendimento novo, mas algo que pertence à condição humana concreta, uma presença, digamos assim. (Amatuzzi, 1997, p. 34)

\section{Considerações finais}

Heidegger vê o homem como Ser-nomundo, não só pelo fato de o homem habitar o mundo, mas a maneira pela qual se encontra com as coisas, manipula-as, transaciona e preocupa-se com os outros e coisas num mundo que lhe é familiar. Ele é o único Ser que habita o mundo pre-ocupado.

A existência humana está assim predisposta a, ao transcender o Ser, encontrar-se com a finitude da transcendência, pois, como visto anteriormente, o ir "de" algo "para" algo comporta em si uma temporalidade e uma espacialidade que em si é finitude, sendo essa finitude geradora de angústia para o homem.

A experiência religiosa, ou essa "apercepção" da magnitude transcendental efetiva no homem, ou na vida humana do Ser que é em si sob qualquer potência ou existência, essa recolocação tópica ou, como quer alguns, esses ato de conhecimento pela revelação da fé é uma transição crítica que ocorre no homem em busca de sua auto-realização.
Em momentos de crise, dor e sofrimento, a fé, apresentando-se em forma de oração/prece, capacita o homem a ampliar seus módulos de ser e exercitar assim sua identidade.

A compreensão do acima exposto tem duas chaves; uma em Heidegger, na qual ele expõe a finitude da manifestação do Ser no ente que se manifesta na transcendência do Ser-aí suspenso dentro do nada; outra é encontrada onde a transcendência do Ser manifestar-se-ia na individuação do Ser, e tal manifestação no Ente, ${ }^{8}$ inclusa a angústia nos termos anteriormente citados, mais a fé na revelação teológica, segundo Tillich.

Heidegger e Tillich estiveram todo o tempo preocupados com a questão do Ser, seus problemas, seu esquecimento e a situação atual em que o homem se encontra. Eles vão clarificando o conceito do Ser, sua relação com o mundo e sua situação na vida cotidiana. Encontramos aí a busca incessante do homem para encontrar significados para sua existência.

Vemos no Ser, a partir de Heidegger, a questão do Ser-no-mundo. A maneira como este Ser habita o mundo e se relaciona com os demais que estão ao seu redor. Como o homem se encontra com as coisas, transaciona e preocupase com os outros. Em meio à preocupação que ele estabelece com o mundo e em relação ao mundo, ele se angustia - tornando-se um ser angustiado.

A angústia surge do conflito do homem apontado ao nada. O homem, então, se projeta para o futuro, com seu poder de transcendência, colocando-se sempre aberto às possibilidades.

O Ser é Ser finito. Uma mistura do Ser e do não-ser. Sua existência tem significação diante do fato de ele estar fora do seu próprio não-ser. Para que o Ser possa tornar-se atual, é necessário que ele supere seu não-ser relativo, ou seja, seu me on, mas ele não pode estar completamente fora dele. É necessário ao Ser tanto estar fora do ouk on, isto é, não-ser absoluto, como dentro do não-ser relativo. "Se afirmarmos que tudo que existe está fora do nãoser absoluto, afirmamos que está tanto no Ser quanto no não-ser" (Tillich, 1987, p. 259).

8. Ser designa aquela perfeição, pela qual alguma coisa é um ente. 
Para Tillich, o Ser é Ser finito - mistura de Ser e não-ser. Esse Ser, somente tomado pelo infinito e pelo transcendente, chegará até o Ser absoluto.

Assim, esse homem que é um vir-a-ser constante, que busca incessantemente por significados existenciais, por uma existência autêntica, vê-se jogado no mundo, depara-se com a finitude, com a ansiedade e a angústia. O Ser vê-se limitado pelo não-ser. O sofrimento faz com que este homem viva uma forma inautêntica de existência. Essa existência inautêntica do homem em crise é uma forma mascarada de Ser.

Esse homem acometido pela dor e pelo sofrimento anseia por uma ajuda, por uma forma de reconstituir os significados abalados e destruídos. Necessita ressurgir das cinzas, nascer de novo. Reclama para si o direito de ser dono dos seus atos e de sua vida. De poder viver com dignidade, em vida plena e abundante. Sente-se inseguro e carece de novos significados, a fim de que possa novamente acreditar em si e nos outros. Abre às possibilidades.

O existir é muito incerto, pois se desenvolve em um processo cheio de ambigüidades e de riscos. Existir é estar em constante processo. Por essa razão é que precisamos ter coragem para existir, coragem para Ser.

O homem, um vir-a-ser constante, ao se deparar com a dor e o sofrimento, vê os significados de sua existência abalados. Torna-se angustiado, ansioso, chegando a viver uma existência inautêntica, de solidão e vazio, que pode levá-lo ao nada, à morte, ao não-ser. $\mathrm{O}$ sofrimento e a dor podem levar o homem à solidão, que conseqüentemente o levará a autodestruição. Tiram do homem a capacidade de afirmar-se diante da vida.

Afirmar significa mais do que simplesmente aceitar. É mais um aceitar ativo, um dizer sim, não apenas verbal ou mentalmente, mas como uma resposta de toda a personalidade. (May, 1982,p. 183)

O homem, acometido de dor e sofrimento, em crise, sente-se inseguro e carece de novos significados, para que possa novamente acreditar em si próprio e nos outros, retomando assim uma vida saudável e plena, cheia de possibilidades.
Ele não consegue afirmar sua posição entre seus semelhantes. Não consegue afirmar a vida como um todo, não consegue afirmar o universo. Se sente inseguro. Não consegue entrar em acordo com essa insegurança. Ela paralisa seus movimentos e deixa sua personalidade em pânico, carente de confiança e da qualidade correlata à coragem. Sua vida pode ser descrita como carente de significados. Não consegue acreditar em si próprio, nos outros e no universo. (May, 1982, p. 183-184)

Na oração/prece, o homem, acometido de sofrimento e dor, experimenta o contato com o Divino; uma realidade que tira de dentro de si o vazio angustiante e o preenche com valores morais e culturais quando reestrutura a personalidade fragmentada e fragilizada pela crise mas não o cura de suas enfermidades.

A fé se lhe apresenta como ajuda no processo de desespero, da coragem de Ser, de transcender o mundo e a si próprio, projetandose para o futuro, atualizando o passado, e vivendo um presente-passado-futuro com dignidade. Na fé, o homem encontra gosto para a vida, pois esta lhe apresenta a graça salvífica de Deus, porém a teologia, a fé, a oração/prece não encontrarão a cura para a Aids - esta tarefa cabe à ciência (cf. Habermas, 2004).

\begin{abstract}
A man attacked by crisis, pain and suf fering meets and sees itself ahead on a situation or a moment that leads it to the loss of sensible for its existence. In the eagemess reverse speed-to mean its life, this exactly man finds in the religious experience a place that can provide or propitiate a possible reorganization of the meanings, values and directions to it lost and/or shaken by the crisis situation. The faith, the prayer/prece, can be presented the man as a possible mediation of this movement to the self-transcendence in relation to the direction of its to exist, however not as are of its diseases.
\end{abstract}

Key-words: religious experience; prayer/pray; crisis.

\section{Referências}

AMATUZZI, Mauro Martins. A experiência religiosa: uma pesquisa em andamento. In: A psicologia e o senso religioso: anais do seminário. Ribeirão Preto: Salus - Associação para a Saúde, 1997.

BARRÍA, C. T. Em torno da doutrina sartreana da conversão. São Bernardo do Campo: Umesp, s/d. [Mimeo.]. 
HABERMAS, Jürgen. Verdade e justificação. São Paulo: Ed. Loyola, 2004.

HEIDEGGER, Martin. Ensaio sobre Anaximandro. Tubingem: Ed. Feick, 1968. [Da edição alemã].

HEIDEGGER, Martin. Ser e tempo (parte I). Petrópolis (RJ): Vozes, 1988.

JAMES, William. As variedades da experiência religiosa - um estudo sobre a natureza humana. São Paulo: Cultrix, 1991.

JOLIVET, Regis. As doutrinas existencialistas - de Kierkegaard a Sartre. 3. ed. Porto (Portugal): Livraria Tavares Martins, 1961.

JOSGRILBERG, Rui de Souza. Vocabulário tillichiano, s/d. [Mimeo.].
MAY, Rollo. A arte do aconselhamento psicológico. 4. ed. Petrópolis (RJ): Vozes, 1982.

PERLS, F. S. A abordagem gestáltica e testemunha ocular da terapia. Rio de Janeiro: GuanabaraKoogan, 1988.

ROMERO, Emílio. A esfera ideal de auto-realização. Antropos Psicologia e Vida, n. 3, São Paulo: Sobraphe, 1988.

SARTRE, J. P. Cahiers pour une morale. Paris: Gallimard, 1983.

TILLICH, Paul. Teologia sistemática. 2. ed. São Paulo/São Leopoldo: Paulinas/Sinodal, 1987. 